\title{
Life paths of familial amiloidotic polyneuropathy patients: a descriptive study
}

\author{
Alice Lopes ${ }^{1 *}$, Alexandra Sousa ${ }^{1}$, Isabel Fonseca', Margarida Branco ${ }^{1}$, Carla Rodrigues$^{1}$, Paula Freitas ${ }^{2}$, \\ Teresa Coelho ${ }^{1}$
}

From First European Congress on Hereditary ATTR amyloidosis

Paris, France. 2-3 November 2015

\section{Background}

Very few studies describe the relations between biographic events, socio-familiar characteristics, and disease during the lifetime of familial amyloid polyneuropathy (FAP) patients.

\section{Methods}

A common social demographic questionnaire and a questionnaire about family history/personal disease and biographic events were applied to 211 subjects (in 110 , the disease had already begun, 82 were asymptomatic carriers, and 19 had no established diagnosis), attending external consultation at Corino de Andrade Unit in Centro Hospitalar do Porto.

A descriptive analysis and frequencies were obtained.

\section{Results}

84 of all subjects were men and 127 were female. Mean ages: carriers $33.9 \pm 9.8 \mathrm{yr}$, patients $37.8 \pm 8.1$, and for subjects that had no established diagnosis $40.9 \pm 14.0 \mathrm{yr}$. Most subjects were married or lived with a partner (67.1\%); 61.5\% had children (mean, 4 children).

Most subjects (96.3\%) had contacted the disease before having their diagnosis, most of them through parents (35.7\%) but also through uncles, grandparents, other family members; the affected parent was the mother in $53.8 \%$ of the cases and the father in $43.3 \%$ of the patients (the remaining did not know who the affected parent was; one patient inherited the disease from both parents); $71.8 \%$ were deceased. Most living parents had symptoms (74.4\%).

Age at time of the affected parent's death: most of the subjects were older than $25 \mathrm{yr}(43 \%)$; the remaining were under $10 \mathrm{yr}$ (9.9\%); between 10 and $14 \mathrm{yr}(15.5 \%)$; and between 15 and $24 \mathrm{yr}$.

Age at time of the parent's disease onset: most of the subjects were under $10 \mathrm{yr}(30.5 \%)$; the remaining were between 10 and $14 \mathrm{yr}$ (14.4\%); between 15 and $24 \mathrm{yr}$ (27.0\%); and $17.2 \%$ were older than 25 yr.

When asked about whether and how their parent's disease had brought changes into their lives, $37.2 \%$ of the subjects said yes, namely through residence, psychological and familial questions.

Most subjects $(53.3 \%)$ had been their parent's caregivers.

About $7.5 \%$ of all patients had been raised through childhood and youth by others, not by their parents.

Some subjects $(8.4 \%)$ refused to acknowledge their own genetic test's result for more than 1 year.

\section{Discussion and conclusions}

Parent's death and the presence of an early-onset disease is a constant in FAP patients' lives and this may be an important distress factor, eventually making them more vulnerable to psychological distress and psychiatric disease.

During childhood, youth, and as young adults, a great number of these patients were obliged to become caregivers and this implied a change of roles in the family.

These results point to a very important psychosocial charge that FAP imposes to patients throughout their lives, since childhood and youth.

\section{Authors' details}

${ }^{1}$ Centro Hospitalar do Porto, Corino de Andrade Unit, 4099-001, Porto, Portugal. ' Universidade do Porto, Instituto de Ciências Biomédicas Abel Salazar, 4050-313, Porto, Portugal.

'Centro Hospitalar do Porto, Corino de Andrade Unit, 4099-001, Porto,

Portugal

Full list of author information is available at the end of the article 
- Convenient online submission

- Thorough peer review

- No space constraints or color figure charges

- Immediate publication on acceptance

- Inclusion in PubMed, CAS, Scopus and Google Scholar

- Research which is freely available for redistribution 